\title{
Threatened common property resource system and factors for resilience: lessons drawn from serege-commons in Muhur, Ethiopia
}

\author{
Mengistu Dessalegn ${ }^{1}$
}

\begin{abstract}
This ethnographic case study of serege-commons, communal pasture and forest in Muhur, Ethiopia, demonstrates the socially complex nature of the common property resource (CPR) system, including the factors behind its resilience and sustained operation. It reveals the multifaceted and interacting local processes that maintain the commons in the face of political economic processes that challenge common property management. The study shows how CPR use, crop cultivation, alternative livelihood strategies, out-migration, collective herding practices, management practices, and alternative sources of compliance interact, and these interacting processes reinforce each other and maintain a resilient CPR system. This study argues that there is not one single cause for sustainable CPR regimes. Instead, the resilience and sustained operation of the CPR system are due to a mix of interdependent elements and inter-reinforcing linkages related to CPR operations, and their interactions within complex social-ecological systems.
\end{abstract}

Key Words: common property resource (CPR); complex social-ecological systems; Muhur; resilience; serege-commons

\section{INTRODUCTION}

Common property resource (CPR) systems constitute an integral part of local livelihood systems, especially in rural societies with long-standing traditions of communal resource use. However, they are often threatened by external challenges. State authorities tend to declare commons as wastelands or as underutilized areas, asserting that their management requires modernization through nationalization or privatization (Brara 1992, Vaccaro et al. 2009, Alden Wily 2011). These negative assumptions reflect in part the legacy of Hardin's 1968 Tragedy of the Commons, which portrayed communal management as inherently vulnerable to environmental collapse. Such assumptions often miss local processes that sustain CPR operations. This paper seeks to demonstrate the multifaceted and interacting local processes that maintain the commons in the face of political economic processes that challenge common property management.

Along with other colleagues, Ostrom $(1990,1999)$ significantly challenged the "tragedy of the commons" thesis, arguing that resource users can self-organize and manage their commons.

Scholars have also offered valuable insights regarding specific regulatory conditions related to successful CPR management. Regular monitoring and enforcement of rules have frequently been identified as the crucial predictors of sustainable CPR regimes (Agrawal and Yadama 1997, Agrawal and Gawal 2001, Ghate and Nagendra 2005, Gibson et al. 2005, Chhatre and Agrawal 2008, Rustagi et al. 2010). This body of work has been helpful in revealing the primacy of monitoring and enforcement of rules to account for sustainable CPR management. On the other hand, relying on this specific factor to account for sustainable CPR management is increasingly problematic at the ground level because local commons have been besieged by external pressures that undermine common property management. We need to understand the processes underpinning CPR operations in the face of such challenges. There is not one single cause for sustainability, but multiple ones. As Agrawal
(2001:1664) remarked, "Multiple causation is a real world phenomenon that most commons scholars need to confront explicitly."

There has been significant progress among commons scholars away from a simplistic approach. Berkes (2006) indicated that cross-level issues are pervasive in commons management, and commons management should be understood as the management of complex systems and deal with cross-level linkages and external drivers. Poteete (2012) underscored that natural resources are affected by multiple factors and linkages. As noted by Barnett and Anderies (2014), what is required is holistic analyses of dynamic interactions among components of complex systems. Ostrom $(2007,2009)$ also emphasized that natural resources used by humans are embedded in complex social-ecological systems and urged moving beyond prescribing simplistic models and panaceas. However, policy makers and resource managers are still implementing simplistic solutions and measures and disregarding multifaceted connections, including commons interdependence with other aspects of livelihoods, livelihood strategies, social arrangements, and community interdependencies. This study demonstrates the problems with ignoring multifaceted factors, linkages, and interactions related to CPR operations.

The study examines how the CPR system in Muhur has continued to operate in a political-ecological context of uncertainty where common property management has been recurrently challenged by political economic processes related to successive political and property regimes. It uses data from detailed ethnographic research on serege-commons, communal grazing and forest areas in Muhur, Ethiopia. It examines the interactions of multiple interdependent elements, connections, and linkages as they pertain to CPR operations. The study examines how CPR use, crop cultivation, alternative livelihood strategies, out-migration, and collective herding practices, as well as management practices and alternative sources of compliance, interact and reinforce each other to maintain the commons, foster resilience, and sustain CPR 
operations. The study makes valuable contributions to resilience, social-ecological systems, and CPR research. It offers a holistic analysis of multiple interdependent elements, linkages, and interactions related to CPR operations, and highlights interreinforcing linkages and interdependencies that foster resilience and maintain the commons. It also demonstrates the importance of situating CPR systems within an often-changing political economic context and understanding how political economic processes interact with CPR operations and social-ecological resilience.

\section{METHODS}

This article is based on a detailed ethnographic study conducted during Ph.D. research completed in 2009. The study took place among the people of Muhur who belong to the Gurage ethnic group whom Shack (1966) referred to as the people of enset (Ensete ventricosum) culture. They live in the Muhur-Aklil wereda (district) of the Gurage zone within the Southern Nations, Nationalities and People's Regional State of Ethiopia (Fig. 1).

Fig. 1. Map showing the location of Muhur.

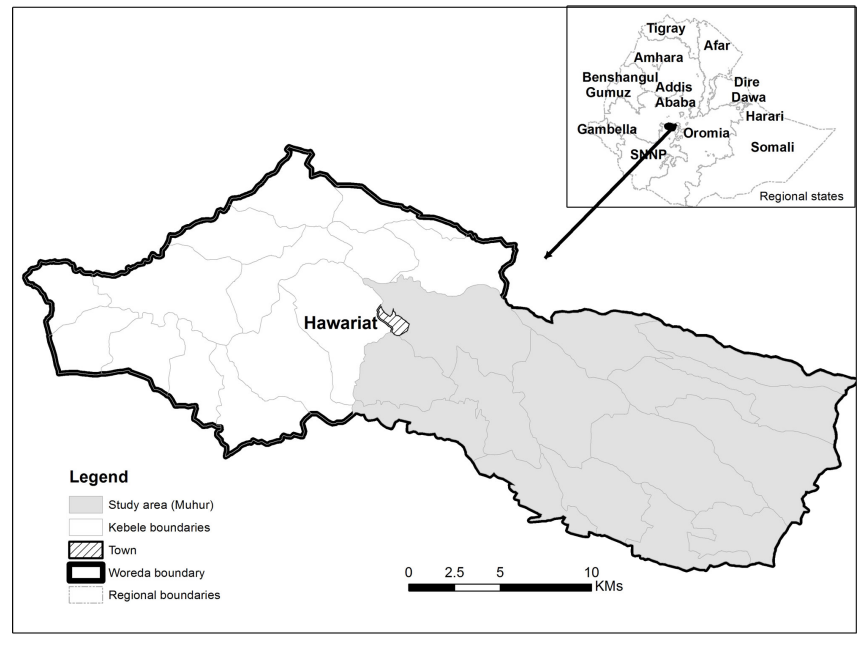

The research focused the serege-commons in four communal areas whose sizes were about 23, 25, 27, and 35 hectares respectively, in four kebeles (subdistricts). The study involved one year of ethnographic field research, employing participant observation, formal and informal interviews, key informant interviews, and group discussions. Participant observation conducted in the course of the field research contributed to a holistic analysis of natural resource management (NRM), livelihoods, and institutional practices as they pertain to CPR operations. Formal and informal interviews were conducted with farmers, migrants, leaders of local and state structures, and agricultural extension officers. Interviews using a semistructured format were carried out with 120 households, comprising 30 farmers in each subdistrict. I also conducted interviews with 20 key informants. A more detailed and comprehensive analysis of these data has been presented in a dissertation examining NRM, institutional practices, and livelihood strategies (Dessalegn 2009). Interview questions, although involving varied patterns as per formal, informal, semistructured, and key informant interviews, generally focused on a number of interrelated issues regarding CPR use and management, institutional practices, socio-cultural values and belief systems, livelihood strategies, agricultural practices, livestock herding, resource use dynamics and history, and localexogenous relations. Participation in various interhousehold, village, and intervillage networks facilitated broader discussions on CPR practices.

Regarding secondary sources, local monastery archives were consulted to assess popular local accounts and spiritual narratives relating to crop cultivation and livestock keeping. Relevant socioeconomic, demographic, and land utilization data were also collected from the district agriculture office and subdistrict administration offices. Data analysis developed through continuous and interrelated processes of analysis and interpretation of field data and field notes. Descriptive, topic, and analytic coding were employed to build categories, themes, patterns, and relationships vis-à-vis CPR operations.

\section{CPR, COMPLEX SYSTEMS, AND RESILIENCE}

The analysis takes a resilience perspective and views CPR systems as complex social-ecological systems (Berkes et al. 2001, Anderies et al. 2006, Berkes 2006, Folke 2006, Folke et al. 2010). A complex system often involves a number of attributes, such as uncertainty, nonlinear dynamics, scale, and self-organization; therefore, it cannot be adequately analyzed using a single perspective (Berkes et al. 2001, Abel and Stepp 2003, Berkes 2006, Folke 2006). A complex system is usually composed of many components that interact with each other, operating as systems, and so cannot be properly understood by detaching and examining specific parts in isolation.

The value of taking a resilience perspective is increasingly recognized as useful for understanding complex systems and the dynamics of social-ecological systems (Berkes et al. 2001, Berkes and Seixas 2005, Carpenter et al. 2005, Anderies et al. 2006, Folke 2006, Folke et al. 2010). Resilience is defined as the capacity of a system to absorb disturbance or the ability to persist despite disturbance and still maintain function (Carpenter et al. 2001, Folke 2006). This capacity of resilience in social-ecological systems also involves adaptive capacity to adjust responses to disturbance, learn, and adapt; self-organizing ability (Berkes et al. 2001, Carpenter et al. 2001, Folke et al. 2002, Folke et al. 2002, Folke 2006, Folke et al. 2010); and transformability through creating a viable arrangement when facing an untenable situation (Walker et al. 2004, Folke et al. 2010).

Social-ecological resilience relates to people and nature as interdependent systems (Folke et al. 2010). This link is particularly reflected in communities that are dependent on ecological resources for their livelihoods (Adger 2000). Building resilience is a key feature for the sustainability of social-ecological systems (Berkes and Seixas 2005). Therefore, it is essential to identify factors that build or sustain resilience at the local level. These factors will often be context dependent and constitute clusters of features that reinforce and complement each other (Berkes and Seixas 2005, Carpenter et al. 2005). The resilience approach emphasizes that a social-ecological system involves connectedness, context, and feedback; thus, understanding sustainability issues requires a holistic analysis of these attributes and their interrelations (Berkes et al. 2001). 
Local CPR systems are not discrete entities. Instead, they are part of political economies and cultural settings that involve power relations along with local-exogenous relations. Political ecology provides valuable insights to analyze these relations and their varied manifestations related to access to and political, economic, and socio-cultural control over resources, and practices and processes of exercising power (Bryant and Bailey 1997, Watts 2000, Paulson et al. 2003, Forsyth 2005). Therefore, understanding both the complexity of a CPR system and its capacity for resilience must involve a detailed political economy carried out through holistic analysis considering political economic processes, power relations, and dynamics.

Extensive scholarship on the commons has revealed the experiences of local users in NRM against Hardin's (1968) pessimistic assumption (e.g., McCay and Acheson 1987, Berkes 1987, Ostrom 1987, 1990, Wade 1987, Feeny et al. 1990, Castro 1995). Along with other colleagues, Ostrom's $(1990,1999)$ work has helped to advance commons scholarship by formulating a set of institutional criteria for commons management. The perspective that has most influenced subsequent understanding of CPR systems has been central in establishing the significance of institutional factors in NRM. One of the important concerns in subsequent analysis has been sorting out which factors are crucial to account for sustainable resource management. Institutions are seen as the rules of the game in society; they are embedded in culture, social relations, and practices (North 1990, Cleaver 2000, 2002, Klooster 2000, Merrey and Cook 2012).

In recent years, there has been an evolution of thinking toward dealing with commons management as the management of complex systems, with emphasis on linkages, self-organization, uncertainty, and resilience (Berkes 2006). There is an appreciation that natural resources used by humans are embedded in complex social-ecological systems, and a better understanding of these systems requires moving beyond the tendency to prescribe simple, predictive models and panaceas (Ostrom 2007, 2009). Thus, examining multidimensional linkages affecting natural resources helps to reveal a broader range of factors, processes, and interactions (Poteete 2012). Scholars have also developed frameworks useful to analyze social-ecological systems (Anderies et al. 2004, McGinnis and Ostrom 2014) and put emphasis on holistic analyses of dynamic interactions (Barnett and Anderies 2014).

It is important to build on relevant progresses within commons scholarship. This article draws on the resilience approach to analyze complex operations, connections, interacting components, and processes related to the CPR system. The resilience approach reinforces the emphasis on the importance of analyzing the combination of interrelated factors and linkages that sustain CPR systems. The resilience approach with the analytical orientations of political ecology provides a useful means of understanding complex CPR systems and their operations in a politicalecological context of uncertainty.

\section{CASE STUDY OF THE CPR SYSTEM IN MUHUR}

\section{Serege-commons, management practices, and challenges}

Serege-commons in Muhur consist of grazing areas and woodland. They are used for grazing, keeping, and herding livestock. The Muhur are sedentary farmers whose system of crop cultivation relies on extensive use of manure. The seregecommons are crucial for keeping livestock and securing access to manure essential for crop production. I return to a detailed discussion of livelihoods, livelihood strategies, resource utilization, and interactions with CPR use in next sections.

Scholars maintain that effective common property regimes involve both inclusive and exclusive notions; i.e., they specify who may use them and who may not (McCay and Acheson 1987). The serege-commons in Muhur operate through inclusion and exclusion arrangements based on kinship and parish membership, and the spatial placement of users around the communal area. Access to resources is permitted or restricted depending on users' customary rights of entitlement and accountability based on their social membership and spatial placement within the socialecological unit of the commons.

Serege-commons are managed through local hierarchical structures, including village, parish, and supra-parish levels. Customary regulations, norms, and practices guide communal resource uses. Attempts to circumvent the local practices using undercover strategies may involve encroaching on parts of the commons and illicit tree cutting. Such transgressions will first be dealt with by the village-based local structure referred to as mode. It is led by a dagna (customary judge) noted for customary dispute-settlement skills. The dagna is aided by a council of elders with customary mediation skills. As I learned through observation of customary proceedings and interviews, dealing with transgressions involves meticulous processes. The case of the commons is defended by yegegn quwami, a customary position represented by a person who functions as a traditional prosecutor on behalf of the commons. Information about alleged transgression is informally disseminated through village social networks. The representative brings the alleged case before the village general assembly. The procedure, depending on the nature of the transgression, involves case explanations, arguments, witnesses, boundary examination, and cultural practices of investigation. Cases are treated and settled through the leadership of the customary judge along with the councils of elders and the assembly. Cases are mostly settled at the village level.

These experiences of common property management refute Hardin's (1968) pessimism regarding local capacity for managing the commons. The sustained operation of the CPR system in Muhur is not, however, based simply on this aspect of commons management alone. Common property management has been recurrently challenged by political economic processes taking place under different political and property regimes. Therefore, adequate understanding of the CPR system, its operations, and its resilience requires a closer examination of the political ecology in which it is situated and the interacting political economic processes. These are related to successive regimes, including the pre-1974 imperial monarchy, the socialist government (1974-1991), and the current market-oriented federal government (1991-present).

The pre-1974 imperial government promoted a very exploitative land institution whereby tenancy was the main form of tenure in the study locality, as in other parts of southern Ethiopia. Stateimposed tenure involved a small number of individuals, members of the aristocracy, officials, and imperial favorites owning extensive tracts that were expropriated from the peasants (Akalu 
Table 1. Major challenges facing the local common property resource (CPR) system by time period.

\begin{tabular}{|c|c|c|c|}
\hline Time period & Challenge/event $^{\dagger}$ & Consequence & Response and outcome \\
\hline $\begin{array}{l}\text { Pre-1974 imperial } \\
\text { monarchy }\end{array}$ & $\begin{array}{l}\text { State officials and absentee } \\
\text { landlords promoted commons } \\
\text { conversion into private holdings }\end{array}$ & $\begin{array}{l}\text { Officials delegitimized serege- } \\
\text { commons } \\
\text { Constant pressure for converting } \\
\text { commons into private cultivation } \\
\text { plots }\end{array}$ & $\begin{array}{l}\text { Persistent local resistance } \\
\text { Ceremonial cursing involving saints conducted } \\
\text { against breaching the commons } \\
\text { Commons preserved and incorporated sacred } \\
\text { attributes }\end{array}$ \\
\hline \multirow[t]{2}{*}{$\begin{array}{l}\text { Socialist government } \\
1974-1991\end{array}$} & $\begin{array}{l}\text { Officials executing land distribution } \\
\text { insisted on distributing the serege- } \\
\text { commons; they endorsed allocation } \\
\text { of commons for farmland }\end{array}$ & $\begin{array}{l}\text { Uncertainty regarding the fate of } \\
\text { commons } \\
\text { Community members divided on } \\
\text { how to accommodate land shortage } \\
\text { and keep the commons }\end{array}$ & $\begin{array}{l}\text { Users opposed distribution arguing that it would } \\
\text { be detrimental to livelihood strategies; instead, } \\
\text { they opted for having less farmland and relying on } \\
\text { kinship tenure } \\
\text { Commons kept out of division through negotiated } \\
\text { agreements }\end{array}$ \\
\hline & $\begin{array}{l}\text { Conflict between local and state } \\
\text { structures; ban on local authority } \\
\text { from organizing and leading } \\
\text { associations }\end{array}$ & $\begin{array}{l}\text { State structures overrode local } \\
\text { authority structures } \\
\text { Undercover enclosure attempts } \\
\text { intensified }\end{array}$ & $\begin{array}{l}\text { Compliance for maintaining the commons was } \\
\text { reinforced through cultural-belief system drawing } \\
\text { on the spiritual support of saints } \\
\text { Local structures recovered eventually } \\
\text { Enclosures reinstated and border markers } \\
\text { implemented }\end{array}$ \\
\hline $\begin{array}{l}\text { Promarket federal } \\
\text { government 1991- } \\
\text { present }\end{array}$ & $\begin{array}{l}\text { District agriculture office suggested } \\
\text { cultivating communal grazing land } \\
\text { to boost grain production }\end{array}$ & $\begin{array}{l}\text { Endorsement for cultivating } \\
\text { commons, and instead using crop } \\
\text { residue for fodder } \\
\text { Disagreement between users and } \\
\text { experts over grazing land use }\end{array}$ & $\begin{array}{l}\text { Users insisted on keeping communal grazing land } \\
\text { use because of intricate linkages between resource } \\
\text { utilization, social arrangements, livelihood } \\
\text { strategies, and the commons } \\
\text { Commons maintained }\end{array}$ \\
\hline
\end{tabular}

These are select instances from each time period.

1982, Rahmato 1985, Shack 1966). The government's tenure system, land policy, and overall power had enormous adverse implications for common property management. Key informants explained that a persistent threat existed against the seregecommons. State officials and absentee landlords often promoted the conversion of the commons into private holdings. They often claimed that commons were "unoccupied" lands to justify their conversions into private holdings.

The socialist government that took power following the collapse of imperial monarchy in 1974 implemented sweeping agrarian reforms. State land reform proclaimed in 1975 nationalized all rural lands, prohibited private ownership of land, and abolished tenancy and landlordism (PMGE 1975, Rahmato 1985). The abolition of tenancy provided relief for peasants who had been suffering from exploitative obligations. However, challenges against the commons continued. Land nationalization gave the state preeminent rights over communal areas, whereas local CPR systems were unacknowledged (Admassie 2000, Pankhurst 2003, Ashenafi and Leader-Williams 2005). The government reforms also brought radical changes in rural governance through the formation of state-created rural structures whose leadership was empowered to implement land redistributions and other administrative activities. Interviews revealed that this change often fostered conflicting relations between local and state structures over commons management.

The current regime, which came to power during the end of the Cold War era in 1991, has moved away from socialism and pursued a promarket economy. However, land ownership continues to be formally vested in the state. Although retaining state ownership of land, the government has recently implemented individual farmland registration to enhance security of usufruct right (e.g., Yami and Snyder 2015). Traditional structures managing the commons lack formal legal recognition. The local structures in Muhur have been dealing with the serege-commons through implicit recognition by state structures because of their longstanding practices. This is a commendable relationship, which offers the possibility of further joint undertakings. However, interviews revealed instances whereby state structures at times act unilaterally. Reported events, for instance, indicate that such unilateral actions may happen to contradict local resource utilization practices (Table 1).

Below is a summary of major challenges facing common property management in Muhur, with ensuing consequences, responses, and outcomes (Table 1). The CPR system has, however, continued to operate despite these challenges. This is because of the interaction of multiple elements and linkages, including alternative sources of compliance, crop cultivation, alternative livelihood strategies, out-migration, collective herding practices, and CPR use. Such a multiplicity of factors, linkages, and interactions characterizes complex social-ecological systems and provides sources of resilience (e.g. Berkes et al. 2001, Berkes 2006, Folke 2006, Poteete 2012). Understanding the resilience and sustained operation of the CPR system in Muhur, therefore, requires a holistic examination of these linkages and interacting processes.

\section{Alternative sources of compliance}

CPR practices in Muhur involve alternative sources of compliance against powerful forces working to undermine local authority structures managing the serege-commons. Compliance has been reinforced through a cultural-belief system that involves the spiritual role of saints. Orthodox Christianity is the religion of most people in Muhur; beliefs about saints and other aspects of the supernatural interact with local ways of life, pervading agricultural and NRM practices. Following rural land and 
governance reforms in the 1970s, for example, state-created rural structures emerged as powerful actors in land administration and rural governance. Interviews and discussions with local respondents indicated that the sovereign power of state structures overrode local authority; officials banned local authorities from organizing and leading associational activities (Table 1). This led to disruption of local structures managing the serege-commons in subsequent years. This situation intensified undercover attempts at enclosures. However, compliance for maintaining the commons was reinforced through the cultural-belief system, invoking spiritual sanctions in the form of saints. For sustainable CPR management, scholars assert the necessity of regular monitoring and rule enforcement through appropriate bodies of persons conducting regular patrols, detecting violators, and implementing punishments (e.g., Agrawal and Goyal, 2001, Ghate and Nagendra 2005, Gibson et al. 2005, Rustagi et al. 2010). The prolonged interruption of local structures managing the serege-commons because of the aforementioned disturbance, however, meant that they would not be able to regularly assemble, attend to transgressions, and impose fines. There was a power vacuum in terms of local structures exercising appropriate authoritative actions. However, compliance for maintaining the commons was reinforced through the cultural-belief system, drawing on the spiritual support and power of saints. Thus, commons management in Muhur draws on diverse sources of power to induce compliance. This situation supports Poteet's (2012) argument for the analysis of linkages that can reveal diverse sources of power influencing actions in social-ecological systems.

Scholars underscore the importance of examining contexts enabling the recovery and renewal of a social-ecological system after disturbance (Abel et al. 2006, Folke 2006). Regarding the disturbance mentioned above, the interaction of alternative sources of compliance helped to sustain compliance and thereby facilitated the recovery of the local structures managing the commons after prolonged interruption. The local structures relied on the context and prospect of this continued compliance and were able to recover with changing leaders and resume operation. They organized resource users and removed enclosures induced by the disturbance, and reintegrated the enclosed areas into the commons (Table 1). They also implemented boundary markers to clearly identify parts of the commons where they appeared obscure. Learning from disturbance is an important process toward renewal of a social-ecological system (Folke 2006). The implementation of boundary markers was based on lessons drawn from enclosures complicated by the disturbance. Local respondents recalled that reclaiming enclosures was problematic because of obscure boundaries, particularly where parts of the commons lie adjacent to individual farmlands. The implementation of boundary markers has improved subsequent management of the serege-commons by enhancing local practices of conflict resolutions over transgressions and boundary disputes. Ostrom $(1990,1999)$ identified clear boundaries as one of the key principles for successful common property management.

Alternative sources of compliance linking the cultural-belief system to preservation of the serege-commons contributed to the resilience of the CPR system in Muhur. Studies that have documented environmental preservation based on sacred groves and forests maintain that people are not, however, consciously using supernatural beliefs to protect resources (e.g., Burman 2000,
2003, Malhotra 2002). However, the link between the belief in saints and sacred attributes associated with the serege-commons in Muhur reveals the integration of NRM practices and the social mechanisms behind such practices (Berkes and Folke 1998, Folke 2006). Local people in Muhur consciously employed their cultural-belief system for maintaining the serege-commons. Insights gained from informants and popular local accounts indicate that ceremonial cursing drawing on the spiritual support of saints and involving collective oaths has been mobilized through parish churches for the preservation of serege-commons. This happened in the 1950s in response to state authorities' and landlords' constant threats against the serege-commons (Table 1). Preservation of the serege-commons has since then incorporated sacred attributes to reinforce compliance against powerful forces working to undermine local authority structures. This is a form of adaptive management of risks related to political and social power relations over resource use (Smit and Wandel 2006).

Ceremonial cursing, along with spiritual sanctions in the form of saints, has reinforced compliance, linking people's belief system, particularly notions of morality and sacredness, to CPR management. Many local people fear supernatural punishments and adhere to the sanctions. A middle-aged farmer emphatically stated that "if an individual adamantly violates serege-commons, his farmland will refuse to produce yield even if he works hard." Key informants also reported cases of individuals' misfortunes as forms of punishments incurred. Individuals also prefer to refrain from violations because of social pressures that link the individual to the society. A young farmer stated that "if a person firmly violated the commons and encountered a problem, people often tend to consider this as a punishment incurred by transgression. The talk of it will spread in the community and the individual will end up being a point of scandal." This will affect the individual in a web of social and cultural spheres including collaboration for agricultural activities, dispute settlement, and risk sharing. Thus, people in Muhur have drawn on notions of morality and sanctioned social relations from their cultural-belief system to reinforce compliance with and cooperation for CPR use. This is an example of "bricolage", which suggests that mechanisms for collective action can be formed through borrowing or constructing from existing sanctioned social relationships, and from multiple sources and patterns of interactions (Cleaver 2000, 2002, Merrey and Cook 2012).

\section{Livelihoods and CPR}

The Muhur are sedentary farmers, combining intensive crop cultivation with keeping livestock. They principally cultivate enset, a root crop that is their staple food. Local farmers appreciate enset's strong drought resistance, which exceeds that of other crops such as grains. Scholars also affirm that enset provides greater protection against drought (e.g., Stevens 1994, Brandt et al. 1997). As noted by Adger (2000), the dependence of communities on natural resources for their livelihoods influences their social resilience to cope with stresses. The serege-commons in Muhur are essential for local livelihood system, but also involve inter-reinforcing linkages between crop cultivation and preservation of the commons. Crop cultivation relies on extensive use of manure. To ensure the supply of manure, livestock must be kept, which in turn requires access to grazing land. The cultivation of the enset essentially depends on livestock keeping, especially for the manure. Popular local accounts and mythology 
regarding enset also narrate the enset-cattle relationship and the use of cow dung for growing it. Thus, enset cultivation, manure use, keeping livestock, access to grazing land, and preservation of the serege-commons are interdependent and reinforce each other.

The serege-commons are vital for keeping livestock and securing access to manure essential for crop cultivation. Cattle constitute the predominant type of livestock kept in the area. The people practice hoe-based cultivation, which does not rely on oxen for ploughing. Cattle are kept primarily for the supply of manure. A farmer insisted that "we are forced to bear the hardships of keeping animals for the sake of dung." Such explanations are widely shared among farmers in the locality. They also assert that having no animals means growing no crops, thereby contributing to contracts between the poor and the prosperous through a shareherding arrangement known as wokie. In this arrangement, poor households receive calves from the rich, allowing access to manure, while they are required to give any new offspring to the lender.

Farmers in Muhur appreciate manure for nourishing the soil and enhancing crop production. One proverb states, "One should not expect yield from the mere planting of enset without yibara (manure) in the same way as a man without knowledge should not expect a girl to marry him." Manuring is performed on a regular basis. Households collect dung from the compartment where animals stay during the night. Every morning, manure accumulated overnight is loaded on a wooden cart, mixed with hay, and transported to farmland. Farmers' awareness and use of organic manure, especially in resource-poor countries, are important factors contributing to food security (e.g., Yang 2006). Manure is a key resource that has enabled sustained crop production in Muhur, enhancing local food security.

Scholars indicated that linkages and connections involved in social-ecological systems and interactions within them are sources of resilience and complexity (e.g., Berkes et al. 2001, Berkes 2006, Poteete 2012). In Muhur, crop cultivation, manure use, keeping livestock, access to grazing land, and preservation of the seregecommons constitute interdependent elements that reinforce each other. Crop cultivation and preservation of the commons are intricately linked and mutually reinforcing. These interreinforcing linkages and interactions helped to develop and sustain the resilience of the CPR system. This has been a vital cause of local resilience against political economic drivers that promote conversion of the commons into individual farmlands. Since the 1975 State's nationalization of all rural lands, land redistributions posed such challenges. The land nationalization act stipulated that "any person who is willing to personally cultivate land shall be allotted rural land sufficient for his maintenance and that of his family" (PMGE 1975, Proc. 31, Article 4). For fulfilling this objective and recurring farmland needs, government had to implement frequent land redistributions that led to undermining of commons sustainability. Continuous land redistributions carried out in the country involved the distribution of communal lands (Rahmato 1985, 2004, Admassie 2001, Adal 2002a, b, Kebede 2002, Ashenafi and Leader-Williams 2005).

The serege-commons in Muhur have, however, been kept out of distribution. The importance of the serege-commons as the foundation of their key livelihood strategy, along with interreinforcing linkages between crop cultivation and preservation of the commons, fostered local resilience to withstand state officials' endorsement of distribution. Interviews revealed that officials implementing land distribution insisted on placing the seregecommons under distribution because of shortage of land (Table 1). They endorsed the conversion of the serege-commons into farmlands. This generated a lot of uncertainty and high tension regarding the continuity of the commons. It also created divisions within community regarding how to accommodate shortages of farmland and maintain the commons. However, community members largely opposed distributing the serege-commons by emphasizing that it would be detrimental to their key livelihood strategy. Alternatively, they opted for having smaller holdings and accommodating children's farmland need within families based on kinship practices. Thus, local users kept the serege-commons out of distribution through negotiated agreements, while sacrificing the option of farmland allotments. The continuity of the local response has been further facilitated through livelihood diversification, along with kinship networks of reciprocities and interdependencies. This has contributed to alleviating the otherwise more extreme agricultural pressure militating against the commons (Dessalegn 2009).

Local resilience in Muhur against external drivers promoting conversion of the commons into farmlands has existed even in the face of compelling internal pressures related to high population and shortage of land. The population density in the area is about 281 persons per square kilometer, and farmland holding size is also very small, ranging between 0.5 and 0.8 hectares (MoARD 2005, SNNPRS 2006, Dessalegn 2009). However, the commons account for a considerable portion, nearly $19 \%$ of the area's land coverage (Table 2). This considerable coverage, despite the prevailing high population and shortage of farmland militating against the commons, reflects the degree of its livelihood significance, necessitating its preservation. This situation corroborates Adger's (2000) observation that the dependence of communities on natural resources for their livelihoods influences their social resilience to cope with stresses.

Table 2. Land utilization in the study district.

\begin{tabular}{lcc}
\hline \hline Utilization & $\begin{array}{c}\text { Land coverage } \\
\text { (hectares) }\end{array}$ & Percentage \\
\hline Land under cultivation & 17,759 & 57.8 \\
Grazing land and natural forest land & 5761 & 18.8 \\
Land not suitable for cultivation & 3280 & 10.7 \\
Covered by roads, settlements, & 3720 & 12 \\
buildings & & \\
Covered by water & 200 & 0.7 \\
Total & 30,720 & 100 \\
\hline
\end{tabular}

Source: Land utilization report obtained during field research from Muhur-Aklil wereda agriculture office.

\section{Rotating herding groups as a resource utilization mechanism}

Local people in Muhur have devised a CPR utilization strategy known as wejo. As discussed below, this mechanism facilitates CPR utilization along with diverse livelihoods, while involving inter-reinforcing linkages that maintain the commons. Wejo is a rotating herding group whereby a single individual assumes 
responsibility for tending the livestock of all the members within a herding group. Membership is based on village residence and involves groups of households. Collective herding operates based on agreed duties and responsibilities, supervised by a herding group leader. A member is required to successfully accomplish his rotational task, making sure that animals are grazing properly, are protected from heat, and are prevented from trespassing onto private farmland. Irregular or poor performance, as well as missing work during a rotation, involves penalties such as doing the job for extra days, while destruction of farmlands by uncontrolled animals entails compensatory fines. However, a household facing serious problems in meeting its obligation can report its predicament to the leader, who will arrange a substitute to cover the task by switching turns, or the household itself can hire a substitute.

Little attention has been given in the literature to the complexity of herd management and its implications for efficient utilization of communal pasture land among sedentary farmers in Africa. Most research on herd management focuses on pastoralist communities, where emphasis is placed on livestock mobility as a means to cope with environmental variability in rangelands (Baker and Hoffman 2006, Butt et al. 2009). My observations in Muhur lead me to emphasize that herd management along with utilization of communal pasture among farming communities involve considerable work, including organizing herds, ensuring that they obtain adequate nutrition from the pasture, ensuring their safety, and preventing them from damaging crops. Such activities essentially compete with other livelihood activities.

People in Muhur endeavor to support their livelihoods through diverse activities. They depend on agriculture, where hoe ploughing, land preparation, planting, and transplanting are laborious and time consuming. They also practice out-migration to generate off-farm income through trading and other activities in towns. Agricultural wage labor is another source of income; it is often provided through wage-labor groups. Such diverse livelihood activities interfere with the use of the commons, livestock grazing, and tending animals, because the tasks of herd management and utilization of communal pasture also involve regular activities. Such competing demands entail competition for a household's labor. Thus, herd management, livestock grazing, and using pasture from the commons would become untenable if a household tried to do the task on its own. However, farmers have managed such competing activities through collective herding. This has enabled them to avoid jeopardizing other vital livelihood activities. Local farmers emphasized the importance of this resource utilization mechanism for permitting them to fulfill their resource use objectives, including communal pasture along with other livelihood activities. This coordination is facilitated by the reciprocities involved in collective herding, which frees up household labor that otherwise would be required for utilizing communal pasture, grazing livestock, and tending animals.

A resilient system should involve adaptability and transformability in terms of responding to challenges as well as coping with tensions through a mechanism that fosters flexibility in the face of untenable situations (Walker et al. 2004, Folke et al. 2010). The CPR system in Muhur reflects such resilience. The collective herding arrangement constitutes a transformation caused by out-migration as a means of livelihood diversification. A combination of economic, demographic, and politicaleconomic factors has played an influential role in shaping the practice of out-migration (Gedamu 1970, Baker 1992, Nida 2000, Dessalegn 2009). Discussions with key informants suggested that the necessity of the collective herding practice grew in response to increased out-migration and urban income activities. This practice of migration to towns particularly increased with increased trading opportunities after the 1960s, along with the development of rural-urban networks enabling people to maximize their economic opportunities (Gedamu 1970, Shack 1973, Baker 1992, Nida 2000). The collective herding arrangement in Muhur has contributed to resilience by facilitating the otherwise untenable task of CPR utilization vis-à-vis seasonal and circular migration. It has made CPR utilization tenable with diverse livelihoods, including out-migration as a source of alternative livelihoods. It has also made out-migration, rural wage labor, and resource utilization more compatible, both directly and indirectly. It reduces overall labor needs and it enables wage-labor groups to be formed. The latter facilitates out-migration because migrants can rely on hired wage-labor groups to help them accomplish their farm activities and move out for off-farm activities. Rural agricultural wage-labor groups also seek to maximize their benefits through such contractual labor relations, because migrants are more willing to pay higher wages to groups so they can quickly complete their farm activities in peak seasons and then return to their town activities. Thus, collective herding has enabled rural-urban mobility and continuity with linked economic benefits for both sides.

Consequently, collective herding and preservation of the seregecommons have become functionally interconnected and mutually reinforcing. Although collective herding is essential to facilitate the demanding task of resource utilization, its operations enable resource use under a common property system. Interviews and discussions conducted with farmers and key informants clearly emphasized this inter-linked operation. Farmers described the importance of serege-commons in relation to collective herding and vice versa. A key informant stated that "we have wejo (collective herding), because we have serege-commons; without serege-commons, there would be no wejo." Such explanations emphasize that collective herding and communal grazing land use are functionally interdependent and inter-reinforce each other. This interdependent and inter-reinforcing relationship between collective herding and preservation of the commons is one of the essential factors that sustain CPR operations and maintain the commons.

Interventions that narrowly equate communal grazing lands with a single dimension of animal feed overlook such complex requirements of resource utilization and inter-reinforcing linkages that sustain self-organized cooperation. For instance, key informants reported that some years ago, the district office of agriculture in the study area suggested the cultivation of communal grazing lands to boost grain cultivation (Table 1). Local users insisted that such areas have been preserved for communal grazing land use. Then, the office suggested that farmers could instead cultivate it and share the crop residue for feeding animals. It misunderstood that this strategy would substitute for the need for a communal grazing land. The suggested resource use change could have brought about the 
collapse of the local CPR system. A move to cultivation would also remove the flexibility of local users to engage in livelihood diversification strategies. However, local users refused the suggestion because of the complex requirements interlinking CPR use, diverse livelihood strategies, and social arrangements for resource utilization; and its implementation was aborted.

Such misreading of communal grazing lands disregards the social arrangements of resource use. This article suggests caution regarding policies and interventions that tend to ban grassland use practices while promoting alternative fodder use. Such interventions may have their own merits where applicable. However, their impacts can differ depending on variations in social-ecological contexts, and they can affect self-organized cooperation. For example, a recent study in China has indicated that the implementation of a grazing ban policy in favor of rearing animals in sheds and using fodder has led to the disappearance of cooperative herding and intensified individualized use of grassland, thereby undermining the sustainable use and management of grasslands (Yu and Farell 2013).

\section{CONCLUSION}

This empirical case study of serege-commons, communal pasture, and forest in Muhur, Ethiopia, documents the socially complex nature of the CPR system, including the factors behind its resilience and sustained operation. The CPR system in Muhur has continued to operate in a political-ecological context of uncertainty where common property management has been recurrently challenged by political economic processes taking place under successive political and property regimes, as well as high population and shortage of land.

CPR operations in Muhur involve multifaceted linkages, connections, and interactions associated with sources of resilience and complexity related to a social-ecological system (e.g., Berkes et al. 2001, Berkes 2006, Poteete 2012). The preservation of the serege-commons is interlinked with the local livelihood system, where crop cultivation relies on extensive use of manure. Ensuring the supply of manure entails keeping livestock, which in turn requires access to grazing land. Crop cultivation and preservation of the serege-commons are, therefore, intricately linked and mutually reinforcing. Collective herding arrangements have made CPR utilization tenable with diverse livelihood strategies, including out-migration as a source of alternative livelihoods. Consequently, collective herding and preservation of the commons have become functionally interconnected and mutually reinforcing. Local management of the serege-commons has also integrated diverse modes of compliance, drawing on local structures of authority, the cultural-belief system, sanctioned socio-cultural relations, and practices of cooperation. Thus, the CPR system cannot be adequately understood in isolation from other linked aspects of livelihoods, livelihood strategies, community interdependencies, socio-cultural relations and practices, power dynamics, and political-economic processes, as well as their interacting processes shaping CPR operations.

The sustained operation of the CPR system in Muhur despite recurring challenges reflects the resilience of the system. Carpenter et al. (2001) suggest that we should clearly specify the "resilience of what to what?" The continued strength of CPR practices in Muhur indicates the social resilience of CPR users to withstand the challenges of changing political economic processes and forces, and sustain CPR operations, thus maintaining a resilient commons along with local agro-ecological sustainability. This study argues that sustained operation of a complex CPR system is not a unilateral function of a specific regulatory condition, nor can it be attributed to a single, predictive causation. There is not one single cause for sustainable CPR regimes.

Instead, the resilience and continuity of CPR operations in Muhur are because of the interactions of a mix of interdependent elements and inter-reinforcing linkages. These include interdependent interactions between key livelihood strategies, including crop cultivation, manure use, keeping livestock, using pasture, access to grazing land, and preservation of the seregecommons; inter-reinforcing linkages between crop cultivation and preservation of the commons, livelihood diversification, social arrangements facilitating coordination between CPR utilization and diverse livelihood activities, interdependent operations, and inter-reinforcing linkages between collective herding practices and preservation of the commons; and alternative and complementary sources of compliance with CPR use and practices of self-organization. The interplay of these multiple elements and inter-reinforcing linkages shaped persistence, adaptability, self-organization, and transformative capacities in response to disturbances and uncertainties, and thus enabled the resilience of the CPR system.

Although these resilience factors are specific to particular contexts, they entail wider implications related to socialecological resilience. First, they underpin the main abilities required for social-ecological resilience, i.e., persistence, selforganization, adaptability, and transformability (Folke 2006, Folke et al. 2010). This confirms the validity of the concept of resilience relating to social-ecological systems. Second, the resilience of the CPR system through a combination of interdependent elements, inter-reinforcing linkages, and interactions corroborates the validity of the idea that factors of resilience should come in clusters and reinforce each other to provide successful sustainability (Berkes and Seixas 2005, Carpenter et al. 2005).

Responses to this article can be read online at: http://www.ecologyandsociety.org/issues/responses. $\mathrm{php} / 8768$

\section{Acknowledgments:}

The author would like to specially thank A. Peter Castro, Hans C. Buechler, and Douglas J. Merrey, whose insightful and valuable comments on the paper helped to improve this article. The support provided by them is greatly appreciated. The author also thanks Sonali Sellamuttu Senaratna for her constructive suggestions. The author is grateful to the anonymous reviewers and editors of Ecology and Society for their critical but constructive comments. The author thanks Yenenesh Abebe for her help with map preparation.

\section{LITERATURE CITED}

Abel, N., D. H. M. Cumming, and J. M. Anderies. 2006. Collapse and reorganization in social-ecological systems: questions, some 
ideas, and policy implications. Ecology and Society 11(1):17. [online] URL: http://www.ecologyandsociety.org/vol11/iss1/ $\underline{\operatorname{art} 171}$

Abel, T., and J. R. Stepp. 2003. A new ecosystems ecology for anthropology. Conservation Ecology 7(3):12. [online] URL: http:// www.consecol.org/vol7/iss3/art12/

Adal, Y. 2002a. Review of land holding systems and policies in Ethiopia under the different regimes. EEA/EEPRI Working Paper No. 5. Ethiopian Economic Association/Ethiopian Economic Policy Research Institute, Addis Ababa, Ethiopia.

Adal, Y. 2002b. Land administration and management of communal land resources in the post-derg period: a case study in two rural kebeles in northwest Ethiopia. Pages 89-118 in W. Nigatu and Y. Adal, editors. Some aspects of rural land tenure in Ethiopia: access, use and transfer. Institute of Development Research, Addis Ababa University, Addis Ababa, Ethiopia.

Adger, W. N. 2000. Social and ecological resilience: are they related? Progress in Human Geography 24(3):347-364. http://dx. doi.org/10.1191/030913200701540465

Admassie, Y. 2000. Twenty years to nowhere: property rights, land management and conservation in Ethiopia. Red Sea Press, Lawrenceville, New Jersey, USA.

Admassie, Y. 2001. Overview of natural resource management in Ethiopia and policy implications. Pages 3-8 in A. Pankhurst, editor. Natural resource management in Ethiopia: proceedings of the workshop organized by Forum for Social Studies in collaboration with the University of Sussex. Forum for Social Studies, Addis Ababa, Ethiopia.

Agrawal, A. 2001. Common property institutions and sustainable governance of resources. World Development 29(10):1649-1672 http://dx.doi.org/10.1016/S0305-750X(01)00063-8

Agrawal, A., and S. Goyal. 2001. Group size and collective action: third-party monitoring in common-pool resources. Comparative Political Studies 34(1):63-93. http://dx.doi.org/10.1177/0010414$\underline{001034001003}$

Agrawal, A., and G. Yadama. 1997. How do local institutions mediate market and population pressures on resources? Forest panchayats in Kumaon, India. Development and Change 28 (3):435-465. http://dx.doi.org/10.1111/1467-7660.00050

Akalu, A. 1982. The process of land nationalization in Ethiopia: land nationalization and the peasants. CWK Gleerup, Lund, Sweden.

Alden Wily, L. 2011. The fate of the commons under global commercial pressure. International Land Coalition, Rome, Italy.

Anderies, J. M., M. A. Janssen, and E. Ostrom. 2004 . A framework to analyze the robustness of social-ecological systems from an institutional perspective. Ecology and Society 9(1):18. [online] URL: http://www.ecologyandsociety.org/vol9/iss1/art18/

Anderies, J. M., B. H. Walker, and A. P. Kinzig. 2006. Fifteen weddings and a funeral: case studies and resilience-based management. Ecology and Society 11(1):21. [online] URL: http:// www.ecologyandsociety.org/vol11/iss1/art21/
Ashenafi, Z. T., and N. Leader-Williams. 2005. Indigenous common property resource management in the central highlands of Ethiopia. Human Ecology 33(4):539-563. http://dx.doi. org/10.1007/s10745-005-5159-9

Baker, J. 1992. The Gurage of Ethiopia: rural-urban interaction and entrepreneurship. Pages 125-147 in J. Baker and P. O. Pedersen, editors. The rural-urban interface in Africa. Nordiska Afrikainstitutet, Uppsala, Sweden.

Baker, L. E., and M. T. Hoffman. 2006. Managing variability: herding strategies in communal rangelands of semiarid Namaqualand, South Africa. Human Ecology 34(6):765-784. http://dx.doi.org/10.1007/s10745-006-9036-y

Barnett, A. J., and J. M. Anderies. 2014. Weak feedbacks, governance mismatches, and the robustness of social-ecological systems: an analysis of the Southwest Nova Scotia lobster fishery with comparison to Maine. Ecology and Society 19(4):39. http:// dx.doi.org/10.5751/ES-06714-190439

Berkes, F. 1987. Common-property resource management and Cree Indian fisheries in sub-Arctic Canada. Pages 66-91 in B. J. McCay and J. M. Acheson, editors. The question of the commons: the culture and ecology of communal resources. University of Arizona Press, Tucson, Arizona, USA.

Berkes, F. 2006. From community-based resource management to complex systems. Ecology and Society 11(1):45. [online] URL: http://www.ecologyandsociety.org/vol11/iss1/art45/

Berkes, F., J. Colding, and C. Folke. 2001. Introduction. Pages 1-30 in F. Berkes, J. Colding, and C. Folke, editors. Navigating social ecological systems: building resilience for complexity and change. Cambridge University Press, Cambridge, UK. http://dx. doi.org/10.1017/cbo9780511541957.003

Berkes, F., and C. Folke, editors. 1998. Linking social and ecological systems: management practices and social mechanisms for building resilience. Cambridge University Press, Cambridge, $\mathrm{UK}$.

Berkes, F., and C. S. Seixas. 2005. Building resilience in lagoon social-ecological systems: a local-level perspective. Ecosystems 8:967-974. http://dx.doi.org/10.1007/s10021-005-0140-4

Brandt, S. A., A. Spring, C. Hiebsch, J. T. McCabe, E. Tabogie, M. Diro, G. Wolde-Michael, G. Yntiso, M. Shigeta, and S. Tesfaye. 1997. The tree against hunger: enset-based agricultural systems in Ethiopia. American Association for the Advancement of Science, Washington, D.C., USA.

Brara, R. 1992. Are grazing lands wastelands? Some evidence from Rajasthan. Economic and Political Weekly 27(8):411-418.

Bryant, R., and S. Bailey. 1997. Third world political ecology. Routledge, London, UK.

Burman, J. J. 2000. Prospects of incorporating sacred groves in environmental management. Pages 105-115 in B. Barik, editor. Resource management and contours of development: reflections through macro-micro narratives. Rawat Publications, New Delhi, India.

Burman, J. J. 2003. Sacred groves among communities: the Mahadeo Kolis and the Kunbis of the western Ghats. Mittal Publications, New Delhi, India. 
Butt, B., A. Shortridge, and A. M. G. A. WinklePrins. 2009. Pastoral herd management, drought coping strategies and cattle mobility in southern Kenya. Annals of the Association of American Geographers 99(2):309-334. http://dx.doi. org/10.1080/00045600802685895

Carpenter, S., B. Walker, J. M. Anderies, and N. Abel. 2001. From metaphor to measurement: resilience of what to what? Ecosystems 4:765-781. http://dx.doi.org/10.1007/s10021-001-0045-9

Carpenter, S. R., F. Westley, and M. G. Turner. 2005. Surrogates for resilience of social-ecological systems. Ecosystems 8:941-944. http://dx.doi.org/10.1007/s10021-005-0170-y

Castro, A. P. 1995. Facing Kirinyaga: a social history of forest commons in southern Mount Kenya. Intermediate Technology Publications, London, UK. http://dx.doi.org/10.3362/9781780444918

Chhatre, A., and A. Agrawal. 2008. Forest commons and local enforcement. Proceedings of the National Academy of Sciences of the United States of America 105(36):13286-13291. http://dx.doi. org/10.1073/pnas.0803399105

Cleaver, F. 2000. Moral ecological rationality, institutions and the management of common property resources. Development and Change 31:361-383. http://dx.doi.org/10.1111/1467-7660.00158

Cleaver, F. 2002. Reinventing institutions: bricolage and the social embeddedness of natural resource management. European Journal of Development Research 14(2):11-30.

Dessalegn, M. 2009. Institutional practices, natural resource management and livelihood strategies in Muhur, south west Ethiopia. Dissertation. Syracuse University, Syracuse, New York, USA.

Feeny, D., F. Berkes, B. J. McCay, and J. M. Acheson. 1990. The tragedy of the commons: twenty-two years later. Human Ecology 18(1):1-19. http://dx.doi.org/10.1007/bf00889070

Folke, C. 2006. Resilience: the emergence of a perspective for social-ecological systems analyses. Global Environmental Change 16:253-267. http://dx.doi.org/10.1016/j.gloenvcha.2006.04.002

Folke, C., S. Carpenter, T. Elmqvist, L. Gunderson, C. S. Holling, and B. Walker. 2002. Resilience and sustainable development: building adaptive capacity in a world of transformations. Ambio 31(5):437-440. http://dx.doi.org/10.1579/0044-7447-31.5.437

Folke, C., S. R. Carpenter, B. Walker, M. Scheffer, T. Chapin, and J. Rockström. 2010. Resilience thinking: integrating resilience, adaptability and transformability. Ecology and Society 15(4):20. [online] URL: http://www.ecologyandsociety.org/vol15/iss4/ $\underline{\operatorname{art} 20 /}$

Forsyth, T. 2005. The political ecology of the ecosystem approach for forests. Pages 165-176 in J. Sayer and S. Maginnis, editors. Forests in landscapes: ecosystem approaches for sustainability. Earthscan, London, UK.

Gedamu, F. 1970. The social and cultural foundation of Gurage associations. Pages 203-213 in Proceedings of the Third International Conference of Ethiopian Studies. Addis Ababa, Ethiopia.

Ghate, R., and H. Nagendra. 2005. Role of monitoring in institutional performance: forest management in Maharashtra, India. Conservation and Society 3(2):509-532.
Gibson, C. C., J. T. Williams, and E. Ostrom. 2005. Local enforcement and better forests. World Development 33(2):273-284. http://dx.doi.org/10.1016/j.worlddev.2004.07.013

Hardin, G. 1968. The tragedy of the commons. Science 162 (3859):1243-1248. http://dx.doi.org/10.1080/19390450903037302

Kebede, B. 2002. Land tenure and common pool resources in rural Ethiopia: a study based on fifteen sites. African Development Review 14(1):113-149. http://dx.doi.org/10.1111/1467-8268.00048

Klooster, D. 2000. Institutional choice, community, and struggle: a case study of forest co-management in Mexico. World Development 28(1):1-20. http://dx.doi.org/10.1016/s0305-750x (99)00108-4

Malhotra, K. 2002. Sacred groves as common property resources: an exploratory study. Pages 511-532 in D. Marothia, editor. Institutionalizing common pool resources. Concept Publishing, New Delhi, India.

McCay, B., and M. Acheson. 1987. Human ecology of the commons. Pages 1-34 in B. McCay and J. Acheson, editors. The question of the commons: the culture and ecology of communal resources. University of Arizona Press, Tucson, Arizona, USA.

McGinnis, M. D., and E. Ostrom. 2014. Social-ecological system framework: initial changes and continuing challenges. Ecology and Society 19(2):30. http://dx.doi.org/10.5751/ES-06387-190230

Merrey, D. J., and S. Cook. 2012. Fostering institutional creativity at multiple levels: towards facilitated institutional bricolage. Water Alternatives 5(1):1-19.

MoARD 2005. SNNPR livelihood profile. Livelihoods Integration Unit, Ministry of Agriculture and Rural Development Disaster Management and Food Security Sector, Addis Ababa, Ethiopia.

Nida, W. 2000. Fanonet: ethnohistorical notes on the Gurage urban migration in Ethiopia. Ufahamu: A Journal of African Studies 28(2-3):43-73.

North, D. C. 1990. Institutions, institutional change and economic performance. Cambridge University Press, Cambridge, UK. http://dx.doi.org/10.1017/cbo9780511808678

Ostrom, E. 1987. Institutional arrangements for resolving the commons dilemma: some contending approaches. Pages 250-265 in $\mathrm{B}$. McCay and J. Acheson, editors. The question of the commons: the culture and ecology of communal resources. University of Arizona Press, Tucson, Arizona, USA.

Ostrom, E. 1990. Governing the commons: the evolution of institutions for collective action. Cambridge University Press, New York, New York, USA. http://dx.doi.org/10.1017/CBO9780511807763

Ostrom, E. 1999. Self-governance and forest resources. CIFOR Occasional Paper 20. Center for International Forestry Research, Bogor, Indonesia. http://dx.doi.org/10.17528/cifor/000536

Ostrom, E. 2007. A diagnostic approach for going beyond panaceas. Proceedings of the National Academy of Sciences of the United States of America 104(39):15181-15187. http://dx.doi. org/10.1073/pnas.0702288104

Ostrom, E. 2009. A general framework for analyzing sustainability of social-ecological systems. Science 325:419-422. http://dx.doi.org/10.1126/science.1172133 
Pankhurst, A. 2003. Conflict management over contested natural resources: a case study of pasture, forest, and irrigation in South Wello, Ethiopia. Pages 59-80 in A. Castro and E. Neilsen, editors. Natural resource conflict management case studies: an analysis of power, participation and protected areas. Food and Agricultural Organization of the United Nations, Rome, Italy.

Paulson, S., L. L. Gezon, and M. Watts. 2003. Locating the political in political ecology: an introduction. Human Organization 62(3):205-217. http://dx.doi.org/10.17730/humo.62.3. e5xcind6y8v09n6b

Poteete, A. R. 2012. Levels, scales, linkages, and other 'multiple' affecting natural resources. International Journal of the Commons 6(2):134-150. http://dx.doi.org/10.18352/ijc.318

Provisional Military Government of Ethiopia (PMGE). 1975. Proclamation to provide for public ownership of rural lands. Proclamation 31/1975. Negarit Gazeta, Addis Ababa, Ethiopia.

Rahmato, D. 1985. Agrarian reform in Ethiopia. Red Sea Press, Trenton, New Jersey, USA.

Rahmato, D. 2004. Searching for tenure security? The land system and new policy initiatives in Ethiopia. FSS Discussion Paper No. 12. Forum for Social Studies, Addis Ababa, Ethiopia.

Rustagi, D., S. Engel, and M. Kosfeld. 2010. Conditional cooperation and costly monitoring explain success in forest commons management. Science 330:961-965. http://dx.doi. org/10.1126/science.1193649

Shack, W. 1966. The Gurage: a people of the ensete culture. Oxford University Press, London, UK.

Shack, W. 1973. Urban ethnicity and the cultural process of urbanization in Ethiopia. Pages 251-285 in A. Southall, editor. Urban anthropology: cross cultural studies of urbanization. Oxford University Press, New York, New York, USA.

Smit, B., and J. Wandel. 2006. Adaptation, adaptive capacity and vulnerability. Global Environmental Change 16:282-292. http://dx. doi.org/10.1016/j.gloenvcha.2006.03.008

Southern Nations, Nationalities and Peoples' Regional State (SNNPRS). 2006. Regional statistical abstract. SNNPRS, Division of Statistics and Population, Hawassa, Ethiopia.

Stevens, J. 1994. A crop that might prevent Ethiopian famine. Bioscience 44(6):393.

Vaccaro, I., L. C. Zanotti, and J. Sepez. 2009. Commons and markets: opportunities for development of local sustainability. Environmental Politics 18(4):522-538. http://dx.doi. org/10.1080/09644010903007393

Wade, R. 1987. The Management of common property resources: collective action as an alternative to privatization or state regulation. Cambridge Journal of Economics 11:95-106.

Walker, B., C. S. Holling, S. R. Carpenter, and A. Kinzig. 2004. Resilience, adaptability and transformability in social-ecological systems. Ecology and Society 9(2):5. [online] URL: http://www. ecologyandsociety.org/vol9/iss2/art5/
Watts, M. 2000. Political ecology. Pages 257-274 in E. Sheppard and T. J. Barnes, editors. A companion to economic geography. Blackwell, Oxford, UK. http://dx.doi.org/10.1002/9780470693445. $\underline{\operatorname{ch} 16}$

Yami, M., and K. A. Snyder. 2015. After all, land belongs to the state: examining the benefits of land registration for smallholders in Ethiopia. Land Degradation and Development http://dx.doi. org/10.1002/1dr.2371

Yang, H. S. 2006. Resource management, soil fertility and sustainable crop production: experiences of China. Agriculture, Ecosystems \& Environment 116:27-33. http://dx.doi.org/10.1016/ j.agee.2006.03.017

Yu, L., and K. N. Farell. 2013. Individualized pastureland use: responses of herders to institutional arrangements in pastoral China. Human Ecology 41(5):759-771. http://dx.doi.org/10.1007/ $\underline{\mathrm{s} 10745-013-9580-1}$ 